\title{
An approach to VD control based on a study in Kingston, Jamaica
}

\author{
WALTER F. GEORGE \\ Public Health Department, S. S. Hope, Kingston, Famaica, and Cornell University Medical College, \\ N.Y., U.S.A.
}

In most countries gonorrhoea tops the list as the most common of the reported venereal diseases, and its incidence is now mounting steeply in all areas of the world (Willcox, 1972). Although the incidence of primary and secondary syphilis has risen markedly in some countries, in others it has been more or less contained. While the rate of primary and secondary syphilis in the U.S.A. during the period 1958 to 1968 has increased from 3.9 to $10 \cdot 3$ per 100,000 population, as reported by the U.S.P.H.S., the rate of gonorrhoea has gradually risen from 142.4 to $219 \cdot 2$ and is still climbing (Fleming, 1972). On the island of Jamaica in the West Indies, the rate of gonorrhoea reported from the eight VD centres during this time gradually increased from a high baseline of 1882.0 per 100,000 population to $2117 \cdot 8$, while the rate of primary and secondary syphilis decreased from $47 \cdot 3$ to $29 \cdot 0$ (Brathwaite, 1971). The rates of other forms of venereal disease in Jamaica for the year 1968 were: non-specific urethritis $46 \cdot 7$, chancroid $2 \cdot 4$, granuloma inguinale $2 \cdot 9$, and lymphogranuloma venereum $3 \cdot 5$. As is the case with reporting in other areas, the magnitude of the venereal disease problem in the U.S.A. and Jamaica is far greater than these figures suggest, since they do not take into account cases treated and not reported by private physicians.

It is therefore obvious that gonorrhoea is the chief venereal disease problem in Jamaica. Of the cases of gonorrhoea reported annually in Jamaica in 1969 and 1970, only one-quarter occurred in women, despite a normal male to female population ratio. The 3:1 ratio of male to female cases is explainable either by the greater promiscuity of men or by the failure to detect asymptomatic female carriers of gonorrhoea. Since culture tests for gonorrhoea were not generally used in Jamaica, the latter explanation seems likely. A diagnosis could be considered reasonably certain in a woman only on epidemiological grounds. Men, on the other hand, pose less of a diagnostic problem, since more than 90 per cent. are symptomatic (Carpenter and Westphal, 1940), and a diagnosis can readily be made by a Gram stain of the urethral discharge. From this it appears that the success of a gonorrhoea control programme would depend on the ability to detect gonorrhoea in asymptomatic women (Lucas, Price, Thayer, and Schroeter, 1967).

In 1971, while working as a member of the Department of Public Health on the S.S. Hope (staffed by volunteer American physicians, medical students, nurses, and technicians), I undertook a study to improve the control of V.D. The immediate objectives of the study were:

(1) To determine the prevalence of gonococcal infection in asymptomatic Jamaican women;

(2) To investigate certain epidemiological factors which might contribute to the high rate of gonorrhoea anticipated in this clinic population;

(3) To evaluate the level of understanding of the disease among women;

(4) To develop a means of reaching more women for the purpose of applying measures of venereal disease control.

This paper discusses the findings of this study and the broader application of this information to the problem of V.D. control.

\section{Material and methods}

178 patients newly admitted to the Victoria Jubilee and Comprehensive Health Centre Antenatal Clinics in Kingston, Jamaica, were included in this study. All were screened for gonorrhoea by smear and culture methods, and some patients were asked a series of questions as part of an epidemiological study. The smears, cultures, and questionnaires were identified by the same code number. 
Since each of the clinics averaged fifty to sixty new patients per 3-hour session and approximately 10 to 15 minutes were required to complete the questionnaire, and since only 4 minutes were necessary to collect specimens from a patient, it was anticipated that it would be impossible to administer the complete questionnaire to every patient. Depending upon how much time was available, from twenty to 35 patients entering the clinics were chosen to take part in the study. The evennumbered patients were asked the full questionnaire and the odd-numbered patients were asked only the first fifty questions (which pertained to use of birth control, education, place of birth, age, and number of children).

\section{Microbiological methods}

All the specimens for smears and cultures were taken concurrently, under direct vision from the endocervix and blindly from the anal canal (Schroeter and Pazin, 1970). Patients with positive tests were referred to the Comprehensive Health Centre Venereal Disease Clinic for treatment and follow-up care.

The specimens were collected on sterile cotton-tipped applicators and were streaked across divided ThayerMartin medium plates prepared from Difco medium, warmed to room temperature, and placed in a candleextinction jar at room temperature. At the conclusion of the clinic session the plates were taken back to the Microbiology Laboratory on the S.S. Hope, where the inoculated areas were cross-streaked, the plates incubated under $\mathrm{CO}_{2}$, and the smears Gram-stained and examined. Cultures with typical colony morphology, a positive oxidase test, and Gram-negative diplococci in sampled colonies were judged to be positive (Schroeter and Pazin, 1970). Smears were considered to be suspicious if Gramnegative intracellular diplococci were identified, but were read as positive only when an accompanying culture was also positive.

\section{Questionnaire}

A female Jamaican medical student interviewed all the women included in this study in a private room at the clinic. Patients were advised as to the personal nature of many of the questions and were told that this information would be kept strictly confidential and that it would be used only by authorized personnel of the S.S. Hope Public Health Department.

In designing the questionnaire, a special effort was made to phrase the questions so that the women, regardless of educational background, could understand them. Care was taken to order the questions so that patients were not led to a particular answer. The questions themselves were worded to encourage spontaneous replies. Included were: chief complaint, use of birth control, place of birth, education, age, knowledge of venereal disease, sexual activity, present and past history of venereal disease, and attitude toward treatment for venereal disease.

The questionnaire was constructed so that every possible reply to a question was identified by a single numerical or alphabetical character; each question was represented on a specific column of an IBM card. From specially designed answer sheets completed by the interviewer, the data was punched onto cards and verified by IBM key punch operators. Computer programming and analysis was done at the Computer Centre of the University of West Indies.

\section{Results}

\section{TESTS FOR GONORRHOEA}

Of the 178 women included in the study, a diagnosis of gonorrhoea was established by culture in twenty patients, giving an infection rate of 11 per cent. (Table I). There was no information regarding infection in their consorts.

TABLE I Laboratory diagnosis of gonorrhoea in the antenatal clinics

\begin{tabular}{|c|c|c|c|}
\hline \multirow[b]{2}{*}{ Health Centre } & \multirow[b]{2}{*}{ No. of patients } & \multicolumn{2}{|c|}{ Gonorrhoea positive } \\
\hline & & No. & Per cent \\
\hline $\begin{array}{l}\text { Comprehensive } \\
\text { Victoria Jubilee }\end{array}$ & $\begin{array}{l}99 \\
79\end{array}$ & $\begin{array}{l}10 \\
10\end{array}$ & $\begin{array}{l}10 \cdot 0 \\
12 \cdot 7\end{array}$ \\
\hline Total & 178 & 20 & $11 \cdot 0$ \\
\hline
\end{tabular}

The most frequently positive culture site was the endocervix, which accounted for 90 per cent. of the positive diagnoses, while 25 per cent. of the positive cultures were from the rectum. By taking cultures from this second site, however, it was possible to diagnose an extra two cases, which represented 10 per cent. of the positive group (Table II).

TABLE II Sources of positive cultures for gonorrhoea

\begin{tabular}{|c|c|c|}
\hline \multirow{2}{*}{ Positive cultures } & \multicolumn{2}{|c|}{ Patients } \\
\hline & No. & Per cent. \\
\hline Total & 20 & 100 \\
\hline Positive cultures and smears & 11 & 55 \\
\hline $\begin{array}{l}\text { Cervical culture and smear } \\
\text { Cervical culture and smear, and } \\
\text { rectal culture }\end{array}$ & $\begin{array}{l}9 \\
2\end{array}$ & $\begin{array}{l}45 \\
10\end{array}$ \\
\hline Positive cultures only & 9 & 45 \\
\hline $\begin{array}{l}\text { Cervical } \\
\text { Rectal } \\
\text { Rectal and cervical }\end{array}$ & $\begin{array}{l}6 \\
2 \\
1\end{array}$ & $\begin{array}{r}30 \\
10 \\
5\end{array}$ \\
\hline
\end{tabular}

\section{QUESTIONNAIRE}

Because the clinic populations from the two antenatal clinics were indistinguishable on the basis of age, education, employment, weekly income, and stage of pregnancy, they were considered as a single population in analysing the results of the questionnaire. 
The typical patient was a 20 to 24-year-old woman, 21 to 23 weeks pregnant, unemployed, and having had 7 to 8 years of primary education. She was born outside Kingston and later moved to the city, where she had been living for at least 5 years. One out of four women worked, and the average income was 6 to 10 Jamaican dollars a week.

Of the 178 women interviewed, 85 were randomly selected to be questioned in addition about their knowledge of venereal disease, sexual activity, and attitude towards treatment for venereal disease. The group subjected to the full questionnaire was made up of 50 per cent. of the women with positive cultures and 47 per cent. of the women with negative cultures.

Knowledge of venereal disease 36 per cent. of the total population could name gonorrhoea as a 'sex disease', 21 per cent. could name syphilis, and 13 per cent. knew the names of gonorrhoea and syphilis. Less than 3 per cent. had not heard of gonorrhoea or syphilis at all. Nearly one-quarter of the women could name at least one correct symptom of gonorrhoea and syphilis in the female and male. While less than 10 per cent. of the patients had heard of a correct cure for venereal disease, three-quarters were aware of the harm that could come to them if they had venereal disease which remained untreated. One-quarter of the women understood that a condom could protect them from venereal disease.

Sexual activity The modal age at first sexual intercourse was 13 to 15 years. 98 per cent. of the women said they had been having sex with the same man for the past 6 months. (A question about marital status was not asked as it was thought that the answers would be unreliable, but it was likely that the majority of women interviewed were living in a common law relationship.) In this population, sexual intercourse occurred at a frequency of two to three times a week. Less than 3 per cent. said they had ever been paid to have sexual intercourse with a man.

Treatment attitudes Patients were asked what course of action they would take if they were discovered to be infected with gonorrhoea. The purpose of this question was to assess the patients' attitudes towards venereal disease treatment and the existing treatment facilities. When asked what they would do if they discovered that the male sex partner had venereal disease, all said they would seek medical attention immediately, preferably at a clinic. Over 75 per cent. said they would be embarrassed to go to a VD clinic, but less than 15 per cent. said they would not seek treatment at a clinic if they suspected they had venereal disease. The most popular clinic for the majority of women was Slipe Pen Road
Comprehensive Health Centre, which offered a variety of medical services, in addition to venereal disease treatment. Patients were also asked if they would tell their male contact that they had just been treated for venereal disease. While over 93 per cent. said they would tell him, the reason for this decision varied; slightly over 50 per cent. of the women had the welfare of their mate in mind. 35 per cent., however, were interested in asking him how he had contracted a venereal disease.

No significant differences in age, education, employment, residence, place of birth, income, knowledge of venereal disease, sexual activity, or attitude to treatment for venereal disease existed between the groups with positive or negative cultures for gonorrhoea.

\section{Discussion}

The population harbouring venereal disease consists of two groups: those who seek medical care and can be effectively treated, and those who do not seek treatment and therefore spread venereal disease. The success of any venereal disease control programme lies in providing medical care for the former group, while concurrently initiating new programmes to deal with the failure of the latter group to obtain treatment.

Overlapping these two groups in distribution is a population which may seek medical attention on a regular basis for non-venereal but sometimes related problems, e.g. antenatal care, birth control, employment medical examinations, etc. This population is an ideal one for venereal disease screening. In the present pilot study of the prevalence of asymptomatic gonorrhoea undertaken in two antenatal clinics in Kingston, Jamaica, 11 per cent. of 178 women tested at a single clinic visit had positive cultures for gonorrhoea. Since the total population attending the two clinics averages 1,500 to 2,000 per year and is asymptomatic for venereal disease, it is apparent that a concerted effort to screen women for gonorrhoea in this population would be worthwhile in terms of disease identification.

The private physician occupies a critical position in determining the effectiveness of any venereal disease control programme, because he has access to a geographically widespread population of patients with venereal disease. In 1968, a national survey of VD incidence in the U.S.A. (Fleming, Brown, Donahue, and Branigin, 1970) showed that more than 75 per cent. of all cases of infectious syphilis and gonorrhoea were treated by private physicians. The survey also indicated that physicians report only 
about 10 per cent. of all VD infections seen. This presents a significant problem when one considers that for each unreported case an average of three potential contacts were lost to tracing by public health epidemiologists. If the Public Health Department made free laboratory services for VD diagnosis available to local physicians, perhaps the trend would change. In any case, a more vigorous effort must be made to enroll private physicians in the battle against venereal disease within their patient population by screening and reporting cases to epidemiologists for contact tracing.

The patients in the Jamaican antenatal clinics, however, would benefit little from the large-scale recruitment of local physicians to participate in venereal disease control, since the majority of such women cannot afford and do not seek private medical care. Since this population is at high risk of having undiagnosed venereal disease, the approach should include a massive screening effort directed at every woman of child-bearing age in the community. The questionnaire responses document their desire for treatment, while demonstrating their woefully inadequate understanding of the signs of venereal disease.

Such a campaign could be conducted by hundreds of neighbourhood women who would be specially educated in the fundamentals of venereal disease diagnosis. There is no reason why these women could not be trained to conduct pelvic examinations, to collect rectal and endocervical samples, to plate these samples on Thayer-Martin transport media (Transgrow), and to take blood for serological testing. The community to be screened could be divided into regions and a team of these paramedical trainees could be responsible for door-to-door visiting in each region. Every woman participating in the screening operation would be equipped with a kit containing disposable specula, sterile applicators, transport medium, gloves, and a portable light. Arrangements could be made for the cultures and blood specimens to be picked up periodically during the day. A second team, consisting of nurses and public health personnel, might contact all persons with positive cultures, treat them at home, and arrange for follow-up treatment in the appropriate clinics. The same group might also do contact tracing. The success of such a massive undertaking depends on gaining public support for the project (Arturi, 1972).

However, population screening is not the final solution to venereal disease control, because some individuals will not cooperate, for reasons such as fear of being embarrassed at a VD clinic, lack of appreciation of the potential seriousness of venereal disease, and ignorance as to where to go for treatment.

In the survey of Jamaican women in antenatal clinics, the level of understanding about venereal disease was low, as manifested by the fact that less than one out of three women could name both gonorrhoea and syphilis as sex diseases, knew the correct treatment for any venereal disease, or was aware that use of the condom could prevent transmission of venereal disease. One cannot help but believe that if women could be taught not to expect any symptoms, then the number of people requesting to be checked for venereal disease, and therefore the number of new cases of venereal disease diagnosed, would increase many times over. The best example of the success of an educational programme in disease prevention can be seen in the results of the campaign to promote early diagnosis of cervical cancer (Christopherson, 1966). If women were instilled with a fear of having venereal disease to the same extent that they fear the development of cancer, then they might insist on obtaining periodic check-ups for venereal disease and on having their male partner use a condom (Arnold and Cogswell, 1971).

The survey made of Jamaican women offers clues as to how such an educational programme should be designed. Since half of the women interviewed had their first sexual experience before the age of 14 to 15 years, it is apparent that a programme of sex and venereal disease education must be initiated in the schools by age 10, if it is to be effective. Furthermore, an effort must be made to educate a large number of young women at home, since 70 per cent. of those interviewed left school before their 8th year of schooling. An intensive venereal disease education campaign using the mass media of communication would be worthwhile, but a more effective way to reach every woman would be through door-to-door visiting by trained neighbourhood women as described above. A 'saturation' educational programme of this kind could be scheduled to prepare the women in the neighbourhood for the screening programme to follow.

People usually feel embarrassed about going to a VD clinic for diagnosis and treatment. This view was shared by three-quarters of the women interviewed in Jamaican antenatal clinics. The Slipe Pen Road Comprehensive Health Centre VD Clinic in Kingston, Jamaica, was the VD clinic which most Jamaican women had in mind when they answered the question about how they would feel about going to a VD clinic. The clinic's methods of operation fostered a feeling of embarrassment in its patients. It was isolated in a separate wing of the Health Centre 
complex, and a sign-board outside, 'The Venereal Disease Clinic', left no doubt as to why people went there. Men and women sat on hard, wooden benches and waited to be seen by the limited staff of one or perhaps two physicians. The interviews were conducted in private and the patients were treated courteously by the staff but the general atmosphere of the clinic discouraged patients from attending it.

This clinic's acceptability could have been considerably improved by providing more comfortable and pleasant waiting-room facilities, by calling the patients by number instead of by name, by removing the emotional overtones associated with the term 'VD' by changing the name to 'clinic for venereology and genito-urinary medicine' (Catterall, 1973), and by utilizing the clinic's services to the utmost by widely publicizing its location and daily hours of operation.

\section{Summary}

Gonorrhoea is the chief venereal disease problem in Jamaica. The major obstacle to successful gonorrhoea control in Jamaica has been the inability to locate and treat the large reservoir of asymptomatic female carriers. In an effort to improve the situation, a study was undertaken in two antenatal clinics in Kingston, Jamaica.

Cervical and rectal specimens from 178 consecutive antenatal patients were cultured on Thayer-Martin medium, and Neisseria gonorrhoeae was isolated from twenty women (11 per cent.).

This finding of a high rate of gonorrhoea in asymptomatic women and the results of a questionnaire examining such factors as the patients' knowledge of venereal disease, sexual activity, and attitudes towards treatment for venereal disease, led to the conclusion that a successful venereal disease programme in Kingston, Jamaica, should include:

(1) The screening for venereal disease of all women attending health clinics;

(2) The utilization of trained local women for venereal disease education and screening of other neighbourhood women;

(3) The intensive education of the population concerning personal measures to control venereal disease, beginning at an early age in the schools;

(4) The operation of free, well-publicized centres designed to treat the wide spectrum of venereal and genito-urinary problems in patients with complete confidentiality.

Special thanks are owed to Judith Rose from the Medical School of U.W.I.; to Dr. A. R. Brathwaite, S.M.O. at CHC VD Centre; to Dr. John Wright, Dr. Harold Royaltey, and Dr. William Fleming of the Public Health
Department on the S.S. Hope; to Dr. G. A. Quash and Dr. M. B. Wilson, of the Biochemistry Department at the University of the West Indies; to Prof. Louis Grant and Dr. Sheila King of the Microbiology Department at U.W.I.; to Dr. Russell Manuel, Dr. L. Husting, and Dr. Karl Smith of the Social and Preventive Medicine Department at U.W.I.; to Linda Nims and June Collier of the Microbiology Laboratory on the S.S. Hope; to Judy and Tony Swan and Peter Jutson, of the Computer Programming and Biostatistics Departments at U.W.I.; to Alice Cushing, M.D., and Darwin Palmer, M.D., of the University of New Mexico Medical School; to Sandoz Pharmaceuticals; and to Mike Moran, Nancy Bronstein, and Mickey Breuning.

\section{References}

Arnold, C. B., and Cogswell, B. E. (1971) Amer. F. publ. Hlth, 61, 739

ArTuri, P. A. (1972) Connecticut Med., 36, 547

BrathwaIte, A. R. (1971) S.M.O., Director of VD Programme in Jamaica. Personal communication

Carpenter, C. M., and WestPhal, R. S. (1940) Amer. f. publ. Hlth, 30, 537

Catterall, R. D. (1973) Brit. F. vener. Dis., 49, 126

Christopherson, W. M. (1966) Acta cytol., 10, 6

Fleming, W. L. (1972) Family Physician, 6, 82

—, Brown, W. J., Donahue, J. F., and Branigin, P. W. (1970) F. Amer. med. Ass., 211, 1827

Lucas, J. B., Price, E. V., Thayer, J. D., and Schroeter, A. L. (1967) New Engl. F. Med., 276, 1454

Schroeter, A. L., and Pazin, G. J. (1970) Ann. intern. Med., 72, 553

WILlcox, R. R. (1972) Brit. F. vener. Dis., 48, 163

Moyens d'aborder la lutte contre les maladies vénériennes d'après une étude effectuée à Kingston, Jamaïque

\section{SOMMAIRE}

La gonococcie est le principal problème de vénéréologie à la Jamaĩque. L'obstacle principal, pour réussir à maîtriser la gonococcie à la Jamaĩque, a été l'impossibilité de localiser et de traiter le large réservoir des femmes porteuses de gonocoques sans symptômes. Pour s'efforcer d'améliorer la situation, une étude fut entreprise dans deux cliniques prénatales de Kingston, Jamaïque.

Des prélèvements cervicaux et rectaux de 178 femmes consécutives se présentant aux examens prénataux furent cultivés sur milieu de Thayer-Martin. Neisseria gonorrhoeae fut isolé chez 20 malades (11 pour cent).

En considérant cette découverte d'un haut taux de gonococcie asymptômatique chez les femmes et les résultats d'un questionnaire examinant des facteurs tels que la connaissance des maladies vénériennes, l'activité sexuelle, les attitudes vis-à-vis du traitement de maladies 
vénériennes, on conclut que, dans un programme pouvant réussir dans la lutte contre les maladies vénériennes à Kingston, Jamaïque, il faut inclure:

(1) La recherche systématique des maladies vénériennes chez toutes les femmes se présentant aux cliniques sanitaires.

(2) L'emploi de femmes locales formées pour donner une éducation sur les maladies vénériennes et pour pratiquer des examens systématiques chez les autres femmes du voisinage.

(3) La création de centres gratuits, bien signalés à la population et destinés à traiter les problèmes étendus de la vénéréologie et des infections génito-urinaires où les malades seraient assurés du secret absolu. 